\title{
How Do Combustion and Non-Combustion Products Used Outdoors Affect Outdoor and Indoor Particulate Matter Levels? A Field Evaluation Near the Entrance of an Italian University Library
}

\author{
Vittoria Cammalleri, Daniela Marotta, Carmela Protano, Matteo Vitali $@$, Paolo Villari, \\ Maria Sofia Cattaruzza * and on behalf of the Smoke-free Department Working Group ${ }^{\dagger}$ \\ Department of Public Health and Infectious Diseases, Sapienza University of Rome, 00185 Rome, Italy; \\ vittoria.cammalleri@uniroma1.it (V.C.); daniela.marotta@uniroma1.it (D.M.); \\ carmela.protano@uniroma1.it (C.P.); matteo.vitali@uniroma1.it (M.V.); paolo.villari@uniroma1.it (P.V.) \\ * Correspondence: mariasofia.cattaruzza@uniroma1.it \\ † The Smoke-free Department Working Group members are listed in Appendix A.
}

Received: 17 June 2020; Accepted: 16 July 2020; Published: 18 July 2020

\begin{abstract}
Particulate Matter (PM) is a well-known health risk factor and pollutes both outdoor and indoor air. Using PM as an air pollution indicator, the aims were to assess outdoor and indoor air pollution due to combustion and/or non-combustion products used outdoors and to compare the PM levels emitted by different products. PM with an aerodynamic diameter $\leq 10,4,2.5$ and $1 \mu \mathrm{m}\left(\mathrm{PM}_{10}, \mathrm{PM}_{4}, \mathrm{PM}_{2.5}, \mathrm{PM}_{1}\right)$ was simultaneously measured in two areas, respectively, indoors (with smoking ban) and outdoors (where people commonly smoke) of a university library during the morning and the afternoon of two weekdays. Both combustion and non-combustion products determined a relevant worsening of outdoor air quality, with the highest $\mathrm{PM}_{1}$ levels achieved when a single traditional cigarette $\left(9920 \mu \mathrm{g} \mathrm{m}^{-3}\right)$, a single e-cigarette $\left(9810 \mu \mathrm{g} \mathrm{m}^{-3}\right)$ and three simultaneous traditional cigarettes $\left(8700 \mu \mathrm{g} \mathrm{m}^{-3}\right)$ were smoked. An increase of indoor $\mathrm{PM}_{1}$ levels was found during outdoor smoking/vaping sessions, persisting also after the end of sessions. The results highlighted the need for a revision of smoke-free laws, especially for outdoor areas, to include non-combustion products. In addition, it is essential to make society aware of the dangers of smoking outdoors by implementing health promotion interventions.
\end{abstract}

Keywords: tobacco smoking; air pollution; particulate matter; conventional cigarettes; electronic cigarettes; heat-not-burn tobacco products

\section{Introduction}

Tobacco smoking represents one of the biggest global health hazards and a major public health issue. About seven million people worldwide die every year due to tobacco use [1]. Smoking can determine many negative effects on health through the life-course and dramatically affects the quality of life and life expectancy [2]. It is the main risk factor for the development and manifestation of cardiovascular and pulmonary diseases, including high rates of cancers, especially lung cancer. Indeed, tobacco smoke is a complex aerosol of chemical compounds bound to aerosol particles or free in the gas phase, and it composed of thousands of substances generating by incomplete combustion of tobacco during the smoking of cigarettes and other tobacco products. This smoke contains a number of toxic compounds and groups of chemicals, including carcinogenic agents such as polycyclic aromatic hydrocarbons. The chemical composition of smoke also depends on puff frequency, intensity, volume, and duration at different stages of cigarette consumption [3]. Thus, tobacco products release into 
the environment a great number of pollutants both during their use and when extinguished due to cigarette butts [4].

Traditionally, smoking is associated to the indoor air contamination as it dramatically increases indoor levels of air pollutants, both during and after smoking [5]. Indeed, pollutants persist in the air also when smoking products have been extinguished, representing a risk of passive smoking, also called Environmental Tobacco Smoke (ETS). This is the combination of two phenomena: Second-Hand Smoke (SHS) and Third-Hand Smoke (THS) [6]. ETS is an issue of great public health concern because it has been linked with a large number of pathologies, including cardiovascular, respiratory and neoplastic ones [7-9]. In addition to the worsening of indoor air quality, scientific evidence demonstrated that smoking may also be considered a source of outdoor pollution, since it produces pollutants which can contaminate outdoor air and persist for a long time [10-12].

Recently tobacco companies are marketing new non-combustion products (electronic cigarettes and heat-not-burn tobacco products (HTPs)) with the purpose to reduce toxic exposures and to provide harm reduction for smokers [13]. Although these products appear to emit fewer pollutants than traditional tobacco products [14], they contribute to air contamination and constitute an additional health risk [15-17]. The study of chemicals released during the use of e-cigs and recent HTPs have revealed to contain toxics such as carbonyls, volatile organic compounds (VOCs) and several inorganic elements, including toxic metals such as nickel, zinc and silver. However, a complete characterization of these products is still under evaluation [18]. Very recently, in Italy, the Ministry of Health reported that "it is not possible, at this stage and on the basis of the documentation provided [by the tobacco industry], to recognise the reduction of toxic substances [in HTPs] as compared to products from combustion, under the same conditions of use" [19] Thus, they represent an additional threat for passive smoking exposure

One of the main contaminants emitted by tobacco products is Particulate Matter (PM), that consists of all substances suspended in air in the form of atmospheric aerosols and, regardless of its composition, is a well-known risk factor for human health [20]. PM is categorized in different sizes according to its aerodynamic diameter. Particles especially relevant for human health are equal or smaller than $10 \mu \mathrm{m}$ and called $\mathrm{PM}_{10}$ [15]. Indeed, particles, depending on their dimension, can settle on different levels of respiratory tract, reach the gas exchange regions and penetrate into the bloodstream [21,22]. Consequently, over the years, PM has been associated to several diseases, such as cardiovascular and respiratory disorders $[23,24]$. Besides, $\mathrm{PM}$ is also a major environmental risk factor for the development of some neurodegenerative diseases [25]. Exposure to PM during pregnancy has been linked with negative birth outcomes [26]. In addition, outdoors PM has been classified as Group 1 carcinogen by the International Agency for Research on Cancer (IARC) [20]. PM can pollute both outdoor and indoor air and can derive from natural (fires, volcanic eruptions, etc.) and human (vehicular traffic, heating systems, tobacco smoke) sources [22]. In particular, scientific evidences demonstrated that smoking is one of the major sources of indoor PM both from traditional tobacco products [27] or electronic devices $[28,29]$.

In order to protect human health of smokers and non-smokers from ETS exposure in enclosed environments, many countries introduced smoking bans in indoor public places; also, several countries introduced smoking ban in some outdoor public places, such as hospitals, parks, schools [30]. In particular, the Smoke-free Environment Act 2000 made several outdoor public places smoke free [31]. However, smoking is still allowed in outdoor public areas such as streets, parks, universities, etc., despite the laws and the evidences of its contribution to outdoor pollution and the possibility of ETS exposure also outdoor [10-12,32].

Besides, new possible threats for ETS exposure emerge from the use of electronic cigarettes and heat-not-burn devices. Indeed, while indoor passive smoking risk connected to these products needs additional evidence [17], no studies (to our knowledge) evaluated outdoor air contamination during their use. 
Using PM as a global indicator of air pollution, the aims of the present study were: to assess outdoor air pollution due to combustion and/or non-combustion products smoked outdoor and to speculate on the potential SHS exposure of a subject standing near the smoker/s; to evaluate the contribution of smoking combustion and non-combustion products, smoked outside in the proximity of a building, on its indoor air quality and to compare the levels of PM emitted by different smoking combustion and non-combustion products.

\section{Materials and Methods}

\subsection{Environmental Assessment of Outdoor and Indoor PM Levels}

Levels of PM with an aerodynamic diameter smaller than respectively 10, 4, 2.5 and $1 \mu \mathrm{m}\left(\mathrm{PM}_{10}\right.$, $\mathrm{PM}_{4}, \mathrm{PM}_{2.5}$ and $\mathrm{PM}_{1}$ ) emitted by smoking outdoor combustion products (traditional and hand-rolled cigarettes) and non-combustion products (electronic cigarettes and unheated tobacco products) were measured to assess environmental contamination. This evaluation was part of a university project for the expansion of smoke-free areas.

The PM measurements were performed in two areas, respectively, indoors and outdoors of the "Del Vecchio" library of the Department of Public Health and Infectious Diseases of Sapienza University of Rome. The indoor environment was the library's entrance hallway located at the first floor of the Department, while the outdoor environment was the gallery on the same floor (Figure 1).

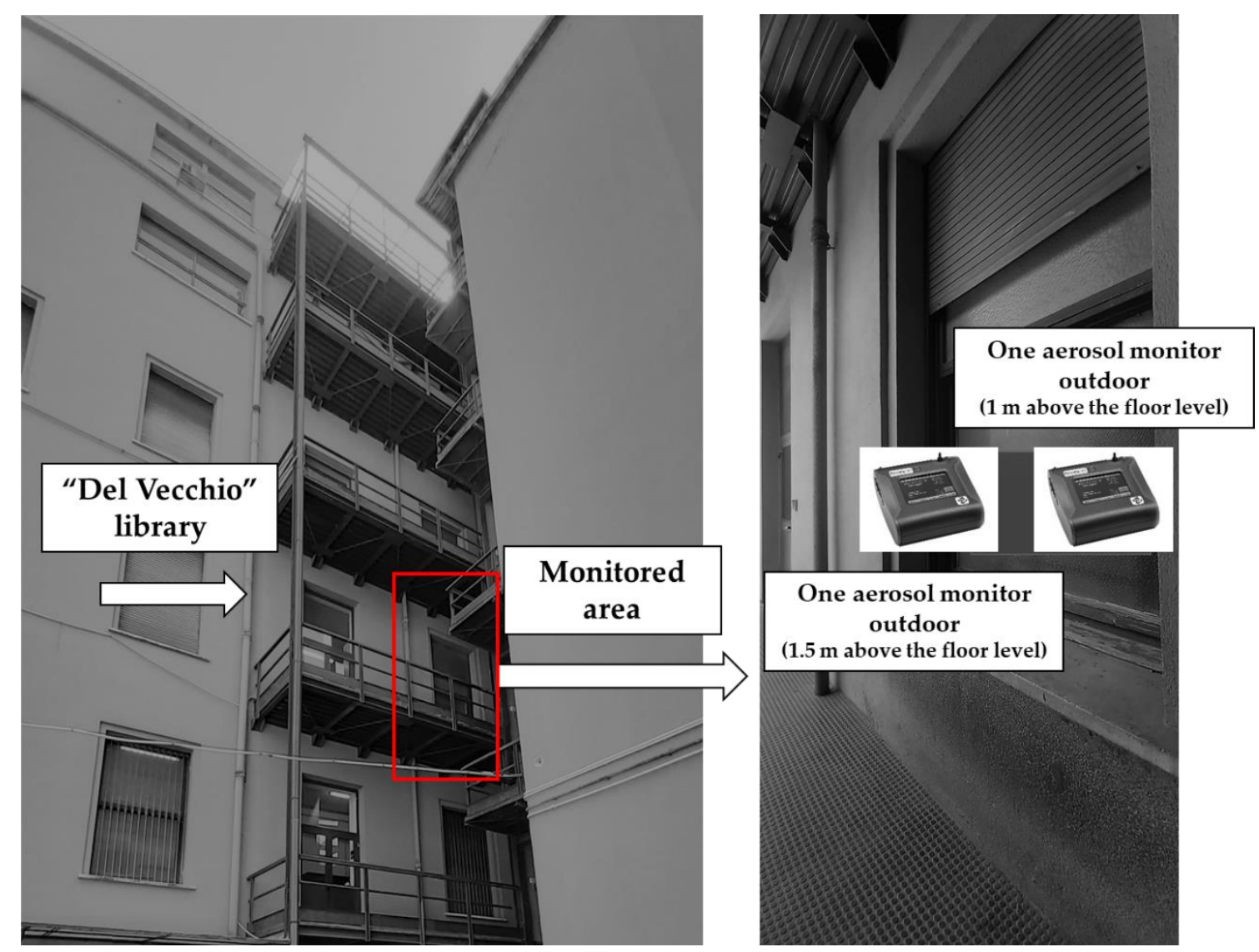

Figure 1. Monitored area.

The library is located in an area without outdoor vegetation nor automobile traffic or other known sources of PM. Outdoor and indoor PM measurements took place during a morning and an afternoon of two typical weekdays. 
In total, a 10-h measurement was performed; types and start/end time of each individual smoked/vaped product were registered. The smokers were university students and employees attending the library. Measurements were performed by means of two portable, laser-operated aerosol mass analyzer Dusttrak TM II Aerosol Monitor, model 8532, 0.1-10 $\mu \mathrm{m}$ particle size range (TSI, Shoreview, MN, USA). The aerosol levels for each size fraction $\left(\mathrm{PM}_{10}, \mathrm{PM}_{4}, \mathrm{PM}_{2.5}, \mathrm{PM}_{1}\right)$, expressed in $\mu \mathrm{g} \mathrm{m}^{-3}$, were measured in "cumulative" mode, that is including the mass of all particles that are smaller than or equal to the defined size. The indoor aerosol was sampled directly through the entry of the instrument, positioned at about $1 \mathrm{~m}$ above the floor level, without using any tube, thus simulating the breathing zone of a passive, exposed, sitting subject. The outdoor aerosol was sampled through a tube placed approximately $1.5 \mathrm{~m}$ above floor level, connected to the second instrument, for simulating the breathing zone of a standing subject.

The indoor air exchange rate $(\lambda)$ was calculated using the tracer gas technique, as previously reported [21]. Mean values of air temperature and relative humidity in indoor and outdoor environments were respectively $26.2{ }^{\circ} \mathrm{C}$ and $44.2 \%$ and $29.7{ }^{\circ} \mathrm{C}$ and $44.4 \%$. Wind conditions were stable and low-dynamic in both the monitoring days. Meteorological parameters were measured by the use of DELTA OHM-HD 32.3 Thermal microclimate instrument (DELTA OHM Srl, PD, Italy) equipped with the probes HP3217R, AP3203, TP3275 (DELTA OHM Srl, PD, Italy) installed near the aerosol monitor indoor and outdoor. Parameters were measured in absence of direct solar irradiation. In addition, we recorded meteorological data of the Meteorological Service of the Italian Air Force headquarters.

\subsection{Comparison of PM Levels Generated by Combustion and Non-Combustion Products}

The levels of PM generated by selected combustion and non-combustion products smoked/vaped during the measuring sessions were compared. In particular, we considered six smoking/vaping sessions in which different products were smoked/vaped: one conventional cigarette (cig), one hand-rolled cigarette (RYO: Rolled Your Own), one electronic cigarette (e-cig), one iQOS ${ }^{\circledR}$ (Philip Morris International), one JUUL ${ }^{\circledR}$ (JUUL Labs, Inc.), one GLO ${ }^{\circledR}$ (British American Tobacco). We compared the PM levels measured from about one minute before to one minute after each of the selected smoking/vaping session.

\subsection{Statistical Analysis}

The Mann-Whitney test was used to assess possible differences in median values of outdoor $\mathrm{PM}_{1}$ measured, respectively, before and during each of the six selected smoking/vaping sessions.

We considered just $\mathrm{PM}_{1}$ fraction because this fraction was the main size range (>95\%) of the aerosol generated during the smoking/vaping sessions. Statistical elaboration was carried out using IBM SPSS Statistics 25 statistical software (IBM Corp., Armonk, NY, USA).

\section{Results}

\subsection{Environmnetal Assessment of Outdoor and Indoor PM Levels}

Figures 2 and 3 show the levels of $\mathrm{PM}_{1}$ measured outdoors and indoors, respectively, during the afternoon and the morning measuring sessions. 

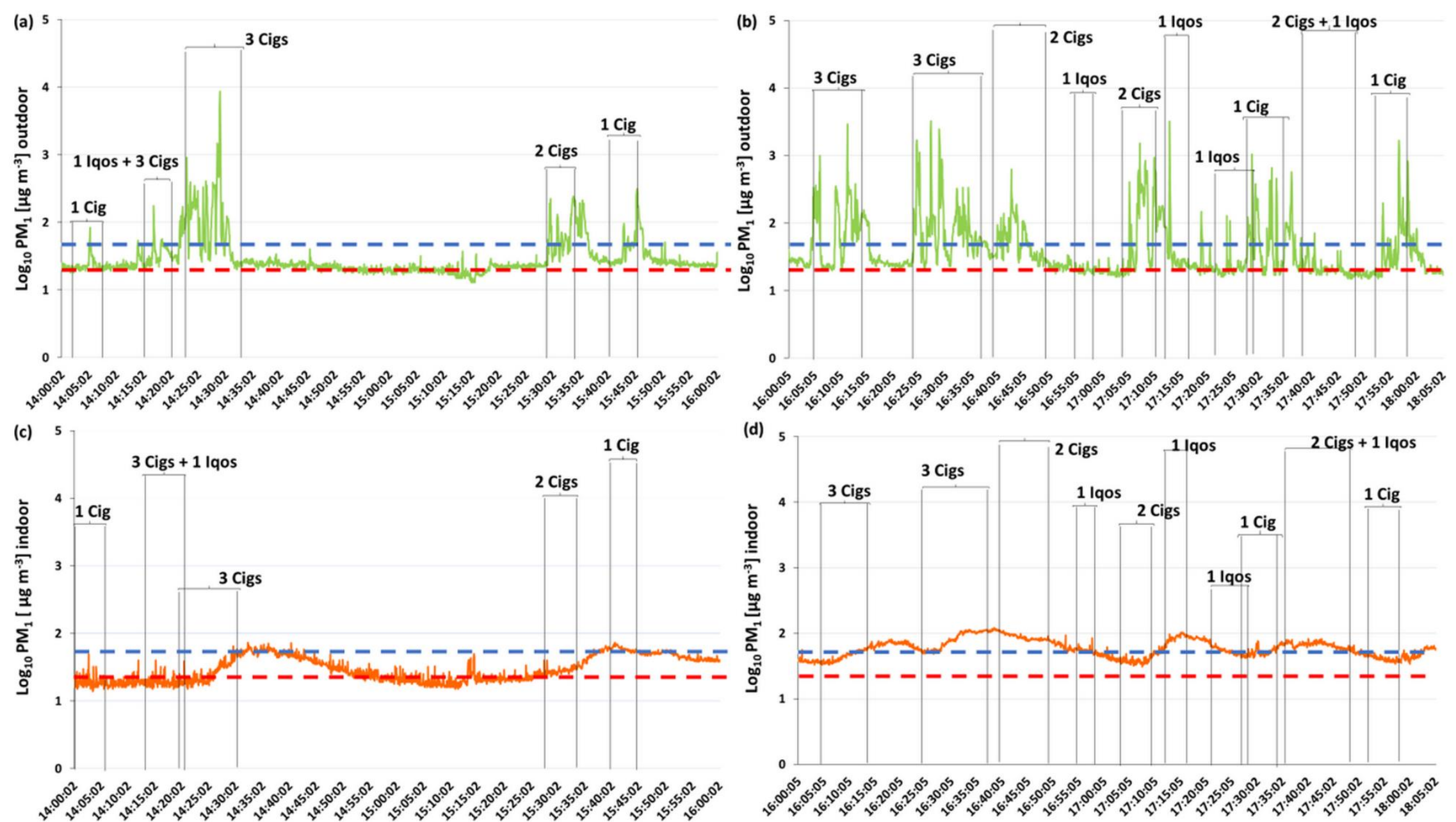

Figure 2. Levels of $\mathrm{PM}_{1}\left(\mu \mathrm{g} \mathrm{m}{ }^{-3}\right)$, expressed in $\log (10) \mathrm{PM}_{1}$, measured, respectively, outdoors $(\mathbf{a}, \mathbf{b})$ and indoors $(\mathbf{c}, \mathbf{d})$ during the afternoon measuring session. 1. $\mathrm{cig}=$ one conventional cigarette; $\mathrm{RYO}=$ "Rolled your own" hand-rolled cigarette; e-cig = electronic cigarette. Red dropped line: $\mathrm{WHO}_{\mathrm{H}}$ guideline value for $\mathrm{PM}_{2.5}$ (24-h mean). Blue dropped line: $\mathrm{WHO}$ guideline value for $\mathrm{PM}_{10}$ (24-h mean). 
Int. J. Environ. Res. Public Health 2020, 17, 5200

6 of 14
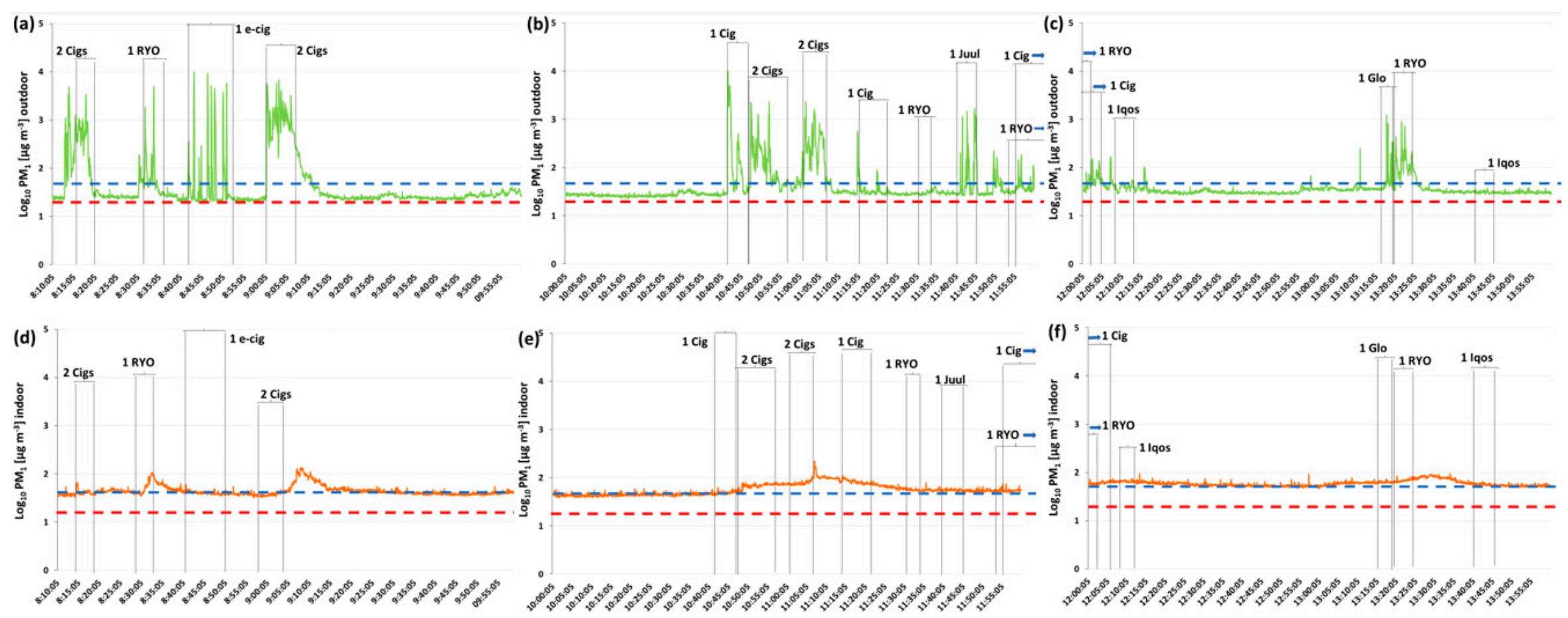

Figure 3. Levels of $\mathrm{PM}_{1}\left(\mu \mathrm{g} \mathrm{m}^{-3}\right)$, expressed in $\log _{(10)} \mathrm{PM}_{1}$, measured, respectively, outdoors $(\mathbf{a}, \mathbf{b}, \mathbf{c})$ and indoors $(\mathbf{d}, \mathbf{e}, \mathbf{f})$ during the morning measuring session. 1. $\mathrm{cig}=$ one conventional cigarette; $\mathrm{RYO}=$ "Rolled your own" hand-rolled cigarette; e-cig = electronic cigarette. Red dropped line: $\mathrm{WHO}_{\mathrm{guideline}}$ value for $\mathrm{PM} \mathrm{M}_{2.5}$ (24-h mean). Blue dropped line: WHO guideline value for $\mathrm{PM}_{10}$ (24-h mean). 
Data reported in Figure 2a,b and Figure 3a-c show a relevant worsening of outdoor air quality during all the smoking sessions. The highest $\mathrm{PM}_{1}$ levels, expressed in $\log _{(10)} \mathrm{PM}_{1}$, are reached when the following products have been smoked: three traditional cigarettes at the same time $\left(8700 \mu \mathrm{g} \mathrm{m}^{-3}\right)$, a single e-cigarette $\left(9810 \mu \mathrm{g} \mathrm{m}^{-3}\right)$ and a single traditional cigarette $\left(9920 \mu \mathrm{g} \mathrm{m}^{-3}\right)$. These values were, respectively, about 323, 446 and 451 times higher the external bottom values. Notice that the outdoor PM levels remain higher than the background level also when the cigarettes or the other products were extinguished. Figure $2 c, d$ and Figure $3 d-f$ ) highlight also an increase of indoor $\mathrm{PM}_{1}$ levels in correspondence to the outdoor smoking/vaping sessions which persisted for a variable period of time even after the end of the sessions.

In both figures, the red and blue dotted lines indicate the WHO air quality guideline values for 24-h mean levels of $\mathrm{PM}_{10}$ and $\mathrm{PM}_{2.5}$ that were, respectively, 25 and $50 \mu \mathrm{g} \mathrm{m}^{-3}$ [33]. Since there were no specific limit values for tobacco smoke, we used WHO values for atmospheric PM levels as landmark values. As evidenced in Figures 2 and 3, $\mathrm{PM}_{1}$ levels are almost always higher than the $\mathrm{PM}_{2.5}$ limit values both indoors and outdoors.

\subsection{Comparison of PM Emission during Selected Smoking/Vaping Session}

In Table 1 are reported the arithmetic mean (AM), with the respective standard deviation (SD), and the median, with the respective interquartile range (IQR), of outdoor $\mathrm{PM}_{1}$ levels found before and during each smoking/vaping session.

Table 1. Outdoor $\mathrm{PM}_{1}$ levels $\left(\mu \mathrm{g} \mathrm{m}^{-3}\right)$ for each device, before and during each smoking/vaping session.

\begin{tabular}{|c|c|c|c|c|c|}
\hline \multirow{2}{*}{$\begin{array}{c}\text { Type of Smoke } \\
\text { Product }\end{array}$} & \multicolumn{2}{|c|}{ Before Smoking/Vaping Session } & \multicolumn{2}{|c|}{ During Smoking/Vaping Session } & \multirow{2}{*}{$p$-Value } \\
\hline & $\mathrm{AM}[\mathrm{SD}]^{1}$ & Median [IQR] ${ }^{2}$ & $\mathrm{AM}[\mathrm{SD}]^{1}$ & Median $[I Q R]^{2}$ & \\
\hline 1 cig * & $18.10[1.58]$ & $18.00[2.00]$ & $106.84[214.07]$ & $44.00[58.00]$ & $<0.001$ \\
\hline RYO * & $25.10[1.04]$ & $25.00[2.00]$ & $221.61[665.99]$ & $57.50[93.00]$ & $<0.001$ \\
\hline e-cig * & $28.81[1.94]$ & $23.00[2.00]$ & $394.82[1317.66]$ & $23.00[29.00]$ & $<0.023$ \\
\hline IQOS $^{\circledR}$ & $39.25[3.34]$ & $39.00[4.00]$ & $46.01[24.09]$ & $41.00[9.00]$ & $<0.181$ \\
\hline$\widetilde{G L O}{ }^{\circledR}$ & $35.85[1.09]$ & $36.00[2.00]$ & $106.30[191.92]$ & $43.00[24.00]$ & $<0.001$ \\
\hline JUUL ${ }^{\circledR}$ & $29.25[1.59]$ & $29.00[2.00]$ & $159.13[304.74]$ & $34.00[107.00]$ & 0.003 \\
\hline
\end{tabular}

${ }^{1} \mathrm{AM}=$ Arithmetic mean, $\mathrm{SD}=$ Standard deviation; ${ }^{2} \mathrm{IQR}=$ Interquartile range. ${ }^{*} 1$ cig $=$ one conventional cigarette; $\mathrm{RYO}=$ "Rolled your own" hand-rolled cigarette; e-cig = electronic cigarette.

The results in Table 1 show an increase in outdoor $\mathrm{PM}_{1}$ levels during the smoking/vaping session compared to the levels measured before the related session for each device. The median outdoor $\mathrm{PM}_{1}$ levels increased from 44.0 to 57.5 for combustion products and from 23.0 to 34.0 for non-combustion products. $\mathrm{PM}_{1}$ levels significantly increase $(p$-value $<0.05)$ for all the monitored devices except for IQOS $^{\circledR}$, which, although not statistically significant, caused a worsening of outdoor air quality. Looking at the AMs and SDs, the values are extremely variable during each smoking/vaping session.

Figure 4 reports the boxplots of outdoor $\mathrm{PM}_{1}$ levels for each device and graphically shows medians with respective IQRs during the smoking/vaping sessions.

RYO and JUUL ${ }^{\circledR}$, respectively one traditional combustion product and a new heat-not-burn device, emitted the highest levels of PM.

Figure 5 shows for each considered product, the $\mathrm{PM}_{1}$ measurement (point by point) performed during each smoking/vaping session, highlighting the presence of peaks of $\mathrm{PM}_{1}$ levels in correspondence of the exhalation of the smoke.

Data reported in Figure 5 show an increase of $\mathrm{PM}_{1}$ levels of 93 and 190 times higher than the outdoor $\mathrm{PM}_{1}$ values before smoking session respectively for conventional cigarette and RYO. As well as considering the outdoor levels of $\mathrm{PM}_{1}$ emitted during the vaping of non-combustion products, we measured several peaks, of about 4, 34, 52 and 427 times higher, respectively, than the background $\mathrm{PM}_{1}$ values, for $\operatorname{IQOS}^{\circledR}, \mathrm{GLO}^{\circledR}, \mathrm{JUUL}^{\circledR}$ and e-cig. 


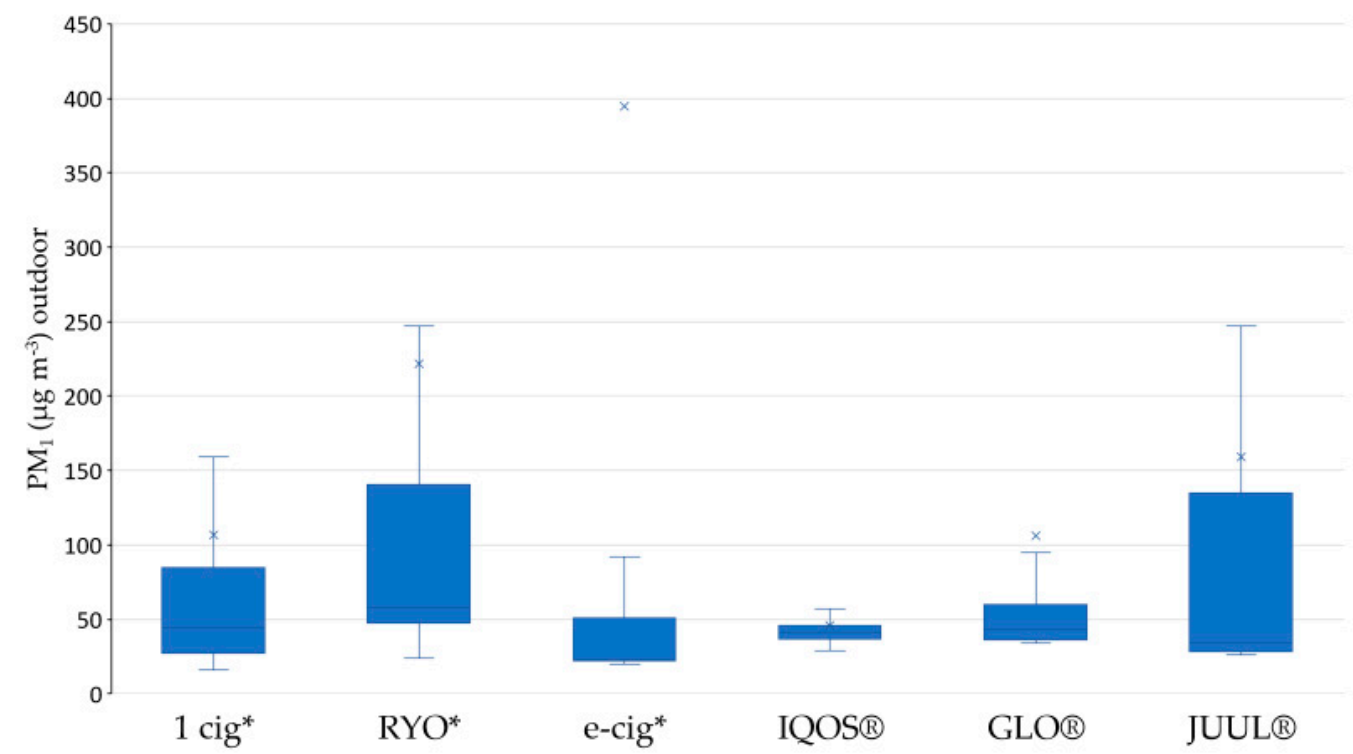

Figure 4. Boxplots of outdoor $\mathrm{PM}_{1}$ levels $\left(\mu \mathrm{g} \mathrm{m}^{-3}\right)$ for each device. ${ }^{*} 1$ cig = one conventional cigarette; $\mathrm{RYO}=$ "Rolled your own” hand-rolled cigarette; e-cig = electronic cigarette.

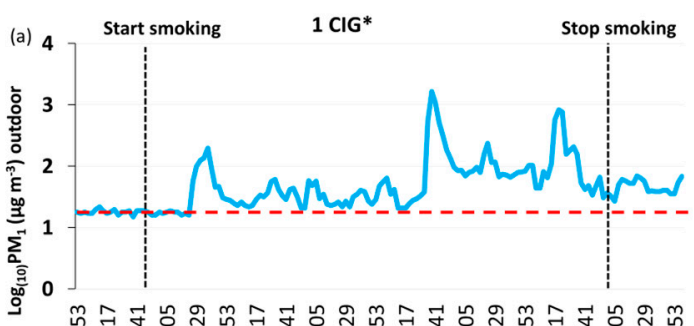

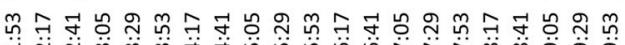

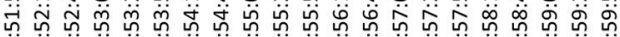

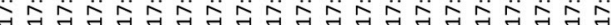

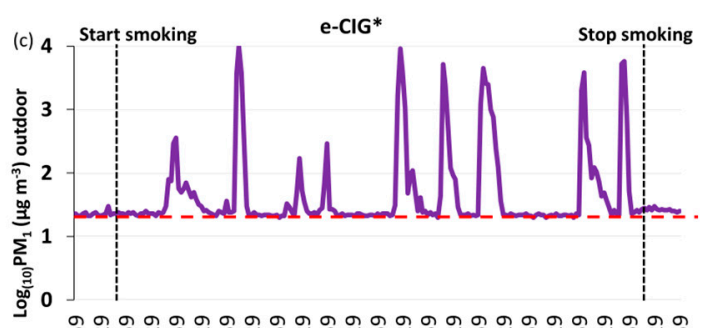

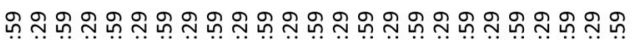

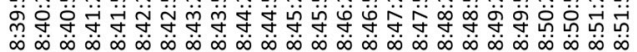

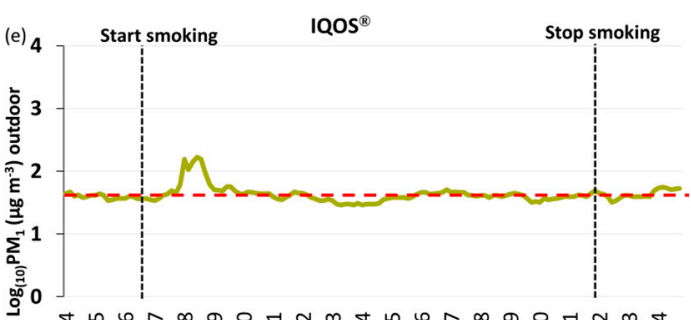

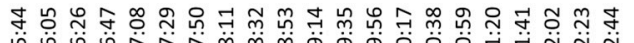

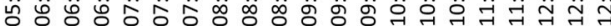



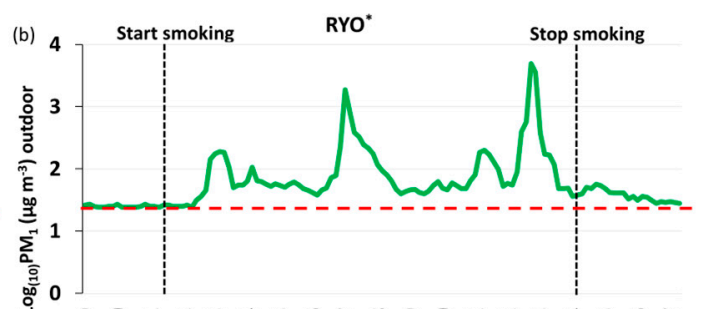

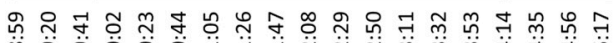

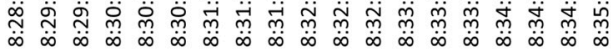
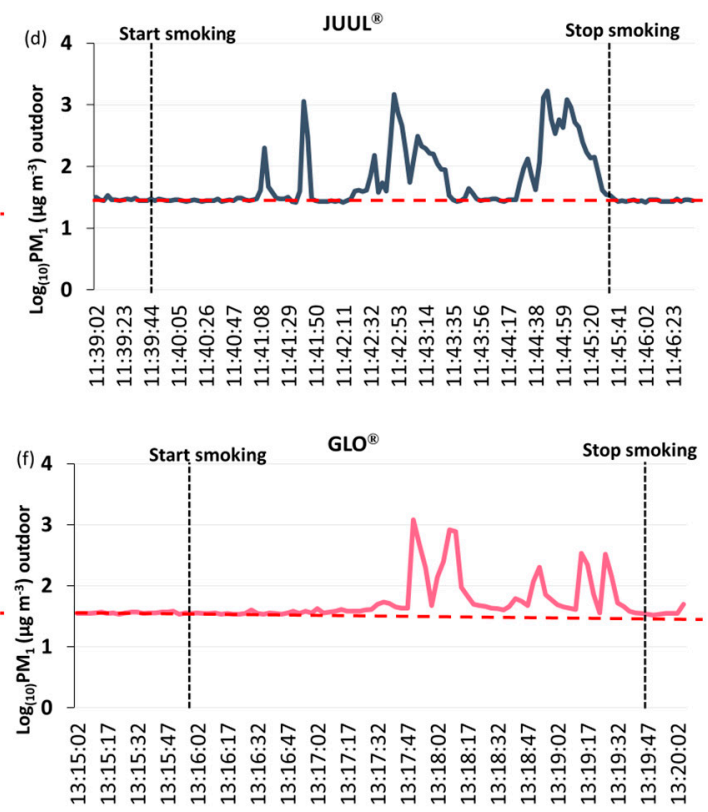

Figure 5. Outdoor $\mathrm{PM}_{1}$ levels (expressed in $\log _{(10)} \mathrm{PM}_{1}$ ), measured point by point, for each device during a smoking/vaping session. Red dropped lines represent the arithmetic mean of outdoor $\log _{(10)} \mathrm{PM}_{1}$, before starting smoking each device. ${ }^{*} 1$ cig = one conventional cigarette; $\mathrm{RYO}=$ "Rolled your own" hand-rolled cigarette; e-cig = electronic cigarette. 
Figure 6 reports the indoor/outdoor ratios of $\mathrm{PM}_{1}$ levels for the environmental level and for smoking/vaping session of each device.

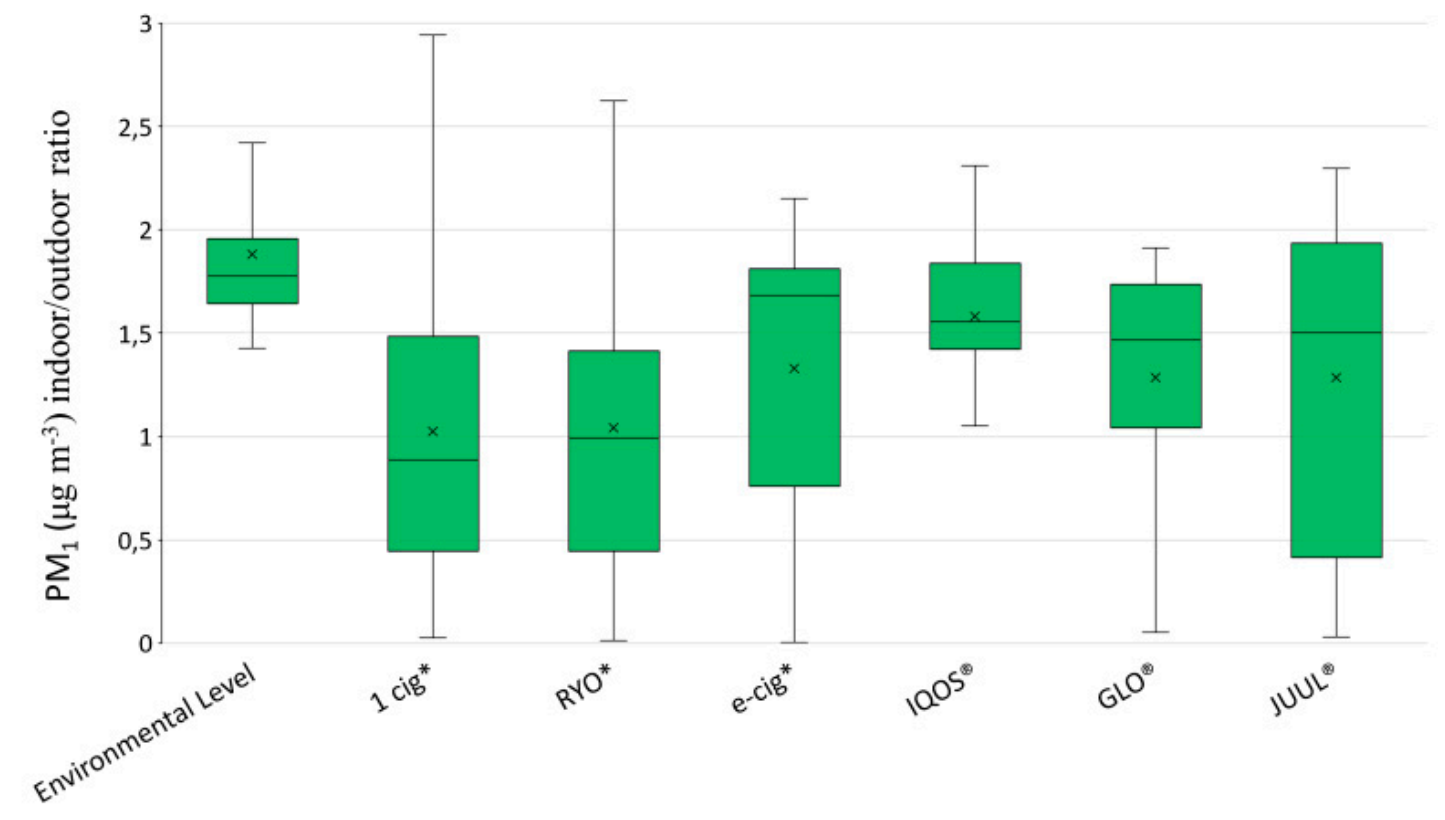

Figure 6. Indoor/outdoor ratios of $\mathrm{PM}_{1}$ levels for environmental level and during the smoking/vaping sessions of each device. * 1 cig = one conventional cigarette; RYO = "Rolled your own" hand-rolled cigarette; e-cig = electronic cigarette.

As shown in Figure 6, the indoor/outdoor ratios of $\mathrm{PM}_{1}$ levels during the smoking/vaping sessions of each device were reduced with respect to the ratio of the environmental level.

\section{Discussion}

The first relevant finding is related to the outdoor $\mathrm{PM}_{1}$ levels registered during the environmental measuring sessions. Indeed, the results demonstrated a worsening of outdoor air quality, during all the smoking/vaping sessions, especially when two or more products were used at the same time. Besides, the outdoor $\mathrm{PM}_{1}$ levels remain higher than the background level even when the cigarettes or the other products were extinguished (Figures 2 and 3). These findings agree with the results of previous studies on outdoor air pollution due to cigarettes and possible exposure to passive smoking outdoors [12,34,35]. In particular, Repace et al. [34] measured the outdoor PM levels in proximity of a group of smokers (up to 10 people) outside the cafeteria entrance of an American university college, demonstrating that $\mathrm{PM}_{2.5}$ raised to $100-150 \mu \mathrm{g} \mathrm{m}^{-3} / 24 \mathrm{~h}$. Ruprecht et al. [12] compared the outdoor air quality by measuring PM levels, respectively, in a high-traffic area and a pedestrian area in which were located a high number of outdoor restaurants and bars, where people commonly smoke. Even though $\mathrm{PM}_{1}$ levels were similar in the two streets during morning hours, in the evening, $\mathrm{PM}_{1}$ levels measured in the pedestrian area were significantly higher (more than twice) with respect to those found in the high traffic street and correlated with the number of cigarettes smoked outdoors. All these results together with those obtained in the present study demonstrate that the common understanding that smoking outdoor is safe must be considered wrong as it leads to the possibility of passive smoke exposure for those close to smokers. In particular, it has been proved that people with respiratory diseases, such as asthma and chronic obstructive pulmonary disease (COPD), who are exposed to short-term SHS in outdoor areas, have a worsening in respiratory parameters [36]. It would be interesting to study the effects of outdoor long-term ETS exposure both in these subjects and in healthy non-smokers.

This consideration can be taken not only for conventional tobacco products, but also for non-combustion products. Indeed, even if the effect of conventional cigarettes on outdoor pollution 
is more relevant, the results of the environmental monitoring demonstrated a significant increase in outdoor $\mathrm{PM}_{1}$ levels both for combustion and non-combustion products. The comparison of the $\mathrm{PM}_{1}$ levels before and during the smoking/vaping session of each selected product (Table 1) confirm a worsening (almost always statistically significant) of outdoor air pollution when combustion and non-combustion products were used. There was only an exception found during the use of an IQOS ${ }^{\circledR}$ $\left(\mathrm{PM}_{1}\right.$ levels ranging from 39.25 [3.34] to 46.01 [24.09], p-value $\left.<0.181\right)$, that may be explained by the fact that e-cig aerosol is only produced during the activation of the device [37] and by specific smoking ways of each smoker. Indeed, we obtained extremely variable values during each smoking/vaping session (Figure 5), that can be due to the specific smoking way, but also to the specific characteristics of each device and the $\mathrm{PM}_{1}$ peaks determined by smoke exhalation during each puff. This is in line with results reported in our previous study on indoor PM contaminations during the indoor use of conventional cigarettes and electronic or heat-not-burn devices [17].

The demonstration of outdoor air pollution and possible ETS exposure determined by combustion and non-combustion products during their use outdoor is of particular importance for all the products. There is still little evidence of outdoor air pollution from smoked combustion products outdoors and, in our knowledge, this is the first study evaluating the outdoor air pollution generated by the outdoor use of non-combustion devices such as $\operatorname{IQOS}^{\circledR}$, JUUL $^{\circledR}$ and GLO ${ }^{\circledR}$. In contrast, these devices are very popular and commonly used worldwide; thus, it is essential to produce scientific evidence for both active and passive vapers. For example, JUUL ${ }^{\circledR}$, one of the most recent electronic devices, was introduced in 2015 and it had captured more than $70 \%$ of the branded e-cigarette market in the United States [38], appealing in particular young people. Besides, Vallone et al. [39], found that in the United States JUUL ${ }^{\circledR}$ use increased from $6.1 \%$ in 2018 to $13.5 \%$ in 2019 for those aged 15-34 years. It should be interesting to measure the SHS exposure of subjects standing near the smoker/s during the use of combustion and non-combustion products by the use of biological markers of exposure, such as urinary cotinine, a well-known indicators of active and passive exposure to smoke [40], urinary unmodified benzene [41], or other substances or their metabolites in biological matrices [42].

As regards to the environmental measurements performed indoor, the results evidence that indoor air quality worsens when combustion and non-combustion products were used outdoor, especially when used simultaneously. These results are in line with those from a previous study performed to evaluate indoor and outdoor ETS levels in some public places presenting indoor smoking bans in Barcelona. For this purpose, the authors measured $\mathrm{PM}_{2.5}$ levels in four locations of each building not potentially exposed to sources of $\mathrm{PM}_{2.5}$ other than tobacco smoke (indoor hall, outdoor main entrance, indoor control and outdoor control areas) and recorded statistically significant higher $\mathrm{PM}_{2.5}$ levels in the hall and the main entrances than in the control areas. A positive association between $\mathrm{PM}_{2.5}$ levels and airborne nicotine levels found in the same locations further confirmed that the source of $\mathrm{PM}_{2.5}$ was the smoke of tobacco products [12]. Similarly, another study was carried out to assess indoor and outdoor ETS levels by measuring $\mathrm{PM}_{2.5}$ levels in some indoor and outdoor areas of some hospitals of the Catalan Network for Smoke-Free Hospitals; the results demonstrated that the highest levels of $\mathrm{PM}_{2.5}$ were registered in outdoor areas, where smoking was allowed [32].

It is important to note that the number of outdoor particles that indoor environments receive is related to the particle infiltration factors, which is characteristic of each environment, to the outdoor aerosol levels and to the particles size distributions [43]. We elaborated the indoor/outdoor ratios for the $\mathrm{PM}_{1}$ levels measured before smoking/vaping session and during the use of each selected device. The results evidenced a reduction of the ratio in all cases respect to the environmental level and a very great variability of the ratio. This finding is in line with those reported by a recent review on this issue, reporting ratios of $\mathrm{PM}_{10}$ and $\mathrm{PM}_{2.5}$ levels widely different between and within indoor and outdoor environments. The indoor/outdoor ratios of PM levels recovered in the revised papers ranged from about the unit (gym, offices, classes, library) to 30 (air-conditioned classroom during cleaning hours in a rainy day [44]). 
Another relevant finding of the present study is related to the comparison between our results and the WHO air quality guideline values for $\mathrm{PM}_{2.5}$ and $\mathrm{PM}_{10}$ : indoor and outdoor $\mathrm{PM}_{1}$ levels are almost always higher than the WHO value for $24-\mathrm{h}$ means $\mathrm{PM}_{2.5}$ levels $\left(25 \mu \mathrm{g} \mathrm{m}^{-3}\right)$. Even, outdoor $\mathrm{PM}_{1}$ levels exceeded the WHO values for 24-h means $\mathrm{PM}_{10}$ levels $\left(50 \mu \mathrm{g} \mathrm{m}^{-3}\right)$ during every smoking/vaping session.

The present study has some limitations. First of all, the study was performed measuring what happens in a real situation where some experimental conditions have not been checked. Indeed, we measured PM levels during the smoking sessions performed by real smokers, and we did not use smoking machine; thus, our results might be influenced by specific ways of smoking. However, the results are relevant because they demonstrated, with objective data, a worsening of both outdoor and indoor air quality when one or more smokers smoked/vaped outdoor. In addition, in our study we measured only the levels of PM and we did not evaluate other pollutants emitted during smoking or vaping. It would, therefore, be desirable to carry out additional experiments under controlled conditions, characterizing the chemical composition of PM and evaluating other substances of the released aerosol that can contaminate indoor and outdoor air.

\section{Conclusions}

All the results presented above highlight two important considerations: firstly, smoking/vaping outdoors causes a relevant increase in $\mathrm{PM}_{1}$ levels in the proximity of the smoker/s determining the possibility of ETS exposure for those who are near the smoker/s, also outdoors. Secondly, smoking/vaping outdoor, but in the proximity of an entrance of a building, causes an increase in indoor $\mathrm{PM}_{1}$ levels, too; this finding means that indoor environments with smoking bans are not entirely free from smoking coming from outside. Thus, these results imply the need for a revision of the smoke-free laws especially for outdoor areas. These laws should also include electronic devices and heat-not-burn products as they determine a significant worsening of outdoor air quality during their use. Indeed, some laws on outdoor smoking bans have already been enacted, but considering outdoor smoking under this relatively new perspective, they should be extended. Thus, it is essential to raise society awareness of the dangers of smoking outdoors by implementing health promotion interventions for outdoor smoking, both for combustion and non-combustion products. Outdoor smoking does not guarantee the safety of non-smokers who are nearby and, therefore, smoking bans should be extended to all outdoor areas of public interest.

Author Contributions: Conceptualization, M.S.C., C.P. and M.V.; methodology, C.P. and M.V.; software, V.C. and D.M.; validation, M.S.C., C.P. and M.V.; formal analysis, V.C. and D.M.; investigation, V.C., D.M. and Smoke-free Department Working Group; data curation, M.S.C. and C.P.; writing_original draft preparation, V.C. and D.M.; writing-review and editing, M.S.C., C.P., M.V. and P.V.; supervision, M.S.C., C.P., M.V. and P.V. All authors have read and agreed to the published version of the manuscript.

Funding: This research received no external funding.

Conflicts of Interest: The authors declare no conflict of interest.

\section{Appendix A}

The Smoke-free Department Working Group Susanna Caminada-Sapienza University of Rome Barbara Dorelli-Sapienza University of Rome

Monica Giffi-Sapienza University of Rome

Matteo Iachini-Sapienza University of Rome

Federica Anna Pirro-Sapienza University of Rome

Roberta Noemi Pocino-Sapienza University of Rome

Matteo Ricciardi-Sapienza University of Rome

Filippo Sandorfi-Alma Mater Studiorum-University of Bologna

Alessandro Sindoni-Sapienza University of Rome 


\section{References}

1. World Health Organization-Tobacco 2019. Available online: https:/www.who.int/news-room/fact-sheets/ detail/tobacco (accessed on 16 February 2020).

2. Pinto, E.; Cruz, M.; Ramos, P.; Santos, A.; Almeida, A. Metals transfer from tobacco to cigarette smoke: Evidences in smokers' lung tissue. J. Hazard. Mater. 2017, 315, 31-35. [CrossRef]

3. Centers for Disease Control and Prevention (US); National Center for Chronic Disease Prevention and Health Promotion (US); Office on Smoking and Health (US). How Tobacco Smoke Causes Disease: The Biology and Behavioral Basis for Smoking-Attributable Disease: A Report of the Surgeon General; Centers for Disease Control and Prevention (US): Atlanta, GA, USA, 2010. Available online: https://www.ncbi.nlm.nih.gov/books/NBK53017/ (accessed on 5 July 2020).

4. Marinello, S.; Lolli, F.; Gamberini, R.; Rimini, B. A second life for cigarette butts? A review of recycling solutions. J. Hazard. Mater. 2020, 384, 121245. [CrossRef] [PubMed]

5. Ni, Y.; Shi, G.; Qu, J. Indoor $\mathrm{PM}_{2.5}$, tobacco smoking and chronic lung diseases: A narrative review. Environ. Res. 2020, 181, 108910. [CrossRef] [PubMed]

6. Protano, C.; Vitali, M. The new danger of third-hand smoke: Why passive smoking does not stop at secondhand smoke. Environ. Health Perspect. 2011, 119, A422. [CrossRef] [PubMed]

7. Pelkonen, M.K.; Laatikainen, T.K.; Jousilahti, P. The relation of environmental tobacco smoke (ETS) to chronic bronchitis and mortality over two decades. Respir. Med. 2019, 154, 34-39. [CrossRef] [PubMed]

8. Flexeder, C.; Zock, J.P.; Jarvis, D.; Verlato, G.; Olivieri, M.; Benke, G.; Abramson, M.J.; Sigsgaard, T.; Svanes, C.; Torén, K.; et al. Second-hand smoke exposure in adulthood and lower respiratory health during 20 year follow up in the European Community Respiratory Health Survey. Respir. Res. 2019, 20, 33. [CrossRef]

9. Lee, W.; Hwang, S.H.; Choi, H.; Kim, H. The association between smoking or passive smoking and cardiovascular diseases using a Bayesian hierarchical model: Based on the 2008-2013 Korea Community Health Survey. Epidemiol. Health 2017, 39, e2017026. [CrossRef]

10. Boffi, R.; Ruprecht, A.A.; Mazza, R.; Ketzel, M.; Invernizzi, G. A day at the European respiratory society congress: Passive smoking influences both outdoor and indoor air quality. Eur. Respir J. 2006, 27, 862-863. [CrossRef]

11. Sureda, X.; Martínez-Sánchez, J.M.; López, M.J.; Fu, M.; Agüero, F.; Saltò, E.; Nebot, M.; Fernàndez, E. Secondhand smoke levels in public building main entrances: Outdoor and indoor PM2.5 assessment. Tob. Control 2012, 21, 543-548. [CrossRef]

12. Ruprecht, A.A.; De Marco, C.; Pozzi, P.; Mazza, R.; Munarini, E.; Di Paco, A.; Paredi, P.; Invernizzi, G.; Boffi, R. Outdoor second-hand cigarette smoke significantly affects air quality. Eur Respir. J. 2016, 48, 918-920. [CrossRef]

13. Yuchuan, H.; Jie, Z.; Dongliang, L.; Ya, D.; Changguo, W.; Kouyan, M.; Jingqiu, C.; Yanrong, L.; Bo, Q.; Fang, X. Circulating biomarkers of hazard effects from cigarette smoking. Toxicol. Ind. Health 2014, 27, 531-535. [CrossRef]

14. Ruprecht, A.A.; De Marco, C.; Pozzi, P.; Munarini, E.; Mazza, R.; Angellotti, G.; Turla, F.; Boffi, R. Comparison between particulate matter and ultrafine particle emission by electronic and normal cigarettes in real-life conditions. Tumori 2014, 100, e24-e27. [CrossRef] [PubMed]

15. Wasel, J.; Boll, M.; Schulze, M.; Mueller, D.; Bundschuh, M.; Groneberg, D.A.; Gerber, A. Brand Cigarillos: Low Price but High Particulate Matter Levels-Is Their Favorable Taxation in the European Union Justified? Int. J. Environ. Res. Public Health 2015, 12, 9141-9153. [CrossRef]

16. Protano, C.; Manigrasso, M.; Avino, P.; Vitali, M. Second-hand smoke generated by combustion and electronic smoking devices used in real scenarios: Ultrafine particle pollution and age-related dose assessment. Environ. Int. 2017, 107, 190-195. [CrossRef] [PubMed]

17. Protano, C.; Manigrasso, M.; Cammalleri, V.; Biondi Zoccai, G.; Frati, G.; Avino, P.; Vitali, M. Impact of Electronic Alternatives to Tobacco Cigarettes on Indoor Air Particular Matter Levels. Int. J. Environ. Res. Public Health 2020, 17, 2947. [CrossRef] [PubMed]

18. Kaur, G.; Muthumalage, T.; Rahman, I. Mechanisms of toxicity and biomarkers of flavoring and flavor enhancing chemicals in emerging tobacco and non-tobacco products. Toxicol. Lett. 2018, 288, 143-155. [CrossRef] [PubMed] 
19. Ministero Della Salute. Prevenzione E Controllo Del Tabagismo. Available online: http://www.salute.gov.it/ imgs/C_17_pubblicazioni_2916_allegato.pdf (accessed on 16 February 2020).

20. International Agency for Research on Cancer. Monographs on the Evaluation of Carcinogenic Risks to Humans; WHO Press: Lyon, France, 2015.

21. Manigrasso, M.; Vitali, M.; Protano, C.; Avino, P. Temporal evolution of ultrafine particles and of alveolar deposited surface area from main indoor combustion and non-combustion sources in a model room. Sci. Total Environ. 2017, 598, 1015-1026. [CrossRef] [PubMed]

22. Manigrasso, M.; Protano, C.; Vitali, M.; Avino, P. Where Do Ultrafine Particles and Nano-Sized Particles Come From? J. Alzheimers Dis. 2019, 68, 1371-1390. [CrossRef]

23. Noh, J.; Sohn, J.; Cho, J.; Kim, C.; Shin, D.C. Long-term effects of fine particulate matter exposures on major adverse cardiovascular events. Int. J. Hypertens. 2016, 34, e202. [CrossRef]

24. Anderson, J.O.; Thundiyil, J.G.; Stolbach, A. Clearing the air: A review of the effects of particulate matter air pollution on human health. J. Med. Toxicol. 2012, 8, 166-175. [CrossRef]

25. Heusinkveld, H.J.; Wahle, T.; Campbell, A.; Westerink, R.H.; Tran, L.; Johnston, H.; Stone, V.; Cassee, F.R.; Schins, R.P. Neurodegenerative and neurological disorders by small inhaled particles. Neurotoxicology 2016, 19, 94-106. [CrossRef] [PubMed]

26. Lamichhane, D.K.; Leem, J.H.; Lee, J.Y.; Kim, H.C. A meta-analysis of exposure to particulate matter and adverse birth outcomes. Environ. Health Toxicol. 2015, 3, e2015011. [CrossRef]

27. Protano, C.; Cattaruzza, M.S.; Osborn, J.F.; Vitali, M. Indoor particulate matter and secondhand smoke: Simulation of an exposure scenario. Ann. Ig. 2014, 26, 186-189.

28. Protano, C.; Avino, P.; Manigrasso, M.; Vivaldi, V.; Perna, F.; Valeriani, F.; Vitali, M. Environmental Electronic Vape Exposure from Four Di_erent Generations of Electronic Cigarettes: Airborne Particulate Matter Levels. Int. J. Environ. Res. Public Health 2018, 15, 2172. [CrossRef] [PubMed]

29. Pellegrino, R.M.; Tinghino, B.; Mangiaracina, G.; Marani, A.; Vitali, M.; Protano, C.; Osborn, J.F.; Cattaruzza, M.S. Electronic cigarettes: An evaluation of exposure to chemicals and fine particulate matter (PM). Ann. Ig. 2012, 24, 279-288. [PubMed]

30. Legislative Degree 12 January 2016, n. 6. Available online: https://www.gazzettaufficiale.it/eli/id/2016/01/18/ 16G00009/sg (accessed on 20 April 2020).

31. Smoke-free Environment Act 2000 No 69. Available online: https://www.legislation.nsw.gov.au/\#/view/act/ 2000/69/full (accessed on 22 April 2020).

32. Sureda, X.; Fu, M.; López, M.J.; Martínez-Sánchez, J.M.; Carabasa, E.; Saltó, E.; Martínez, C.; Nebot, M.; Fernández, E. Second-hand smoke in hospitals in Catalonia (2009): A cross-sectional study measuring PM2.5 and vapor-phase nicotine. Environ. Res. 2010, 110, 750-755. [CrossRef]

33. World Health Organization (WHO). WHO Air Quality Guidelines for Particulate Matter, Ozone, Nitrogen Dioxide, and Sulfur Dioxide; Global Update, 2005; Summary of Risk Assessment; WHO Press: Geneva, Switzerland, 2006.

34. Repace, J.L. Measurements of Outdoor Air Pollution from Secondhand Smoke on the UMBC Campus. Available online: http://www.repace.com/pdf/outdoorair.pdf (accessed on 5 April 2020).

35. Sureda, X.; Bilal, U.; Fernàndez, E.; Valente, R.; Escobar, F.J.; Navas-Acien, A.; Franco, M. Secondhand smoke exposure in outdoor hospitality venues: Smoking visibility and assessment of airborne markers. Environ. Res. 2018, 162, 220-227. [CrossRef]

36. Keogan, S.; Alonso, T.; Sunday, S.; Tigova, O.; Fernández, E.; López, M.J.; Gallus, S.; Semple, S.; Tzortzi, A.; Boffi, R.; et al. Lung function changes in patients with chronic obstructive pulmonary disease (COPD) and asthma exposed to secondhand smoke in outdoor. J. Asthma 2020, 57, 1-7. [CrossRef]

37. Gentzke, A.S.; Creamer, M.; Cullen, K.A.; Ambrose, B.K.; Willis, G.; Jamal, A.; King, B.A. Vital signs: Tobacco product use among middle and high school students-United States, 2011-2018. MMWR Morb. Mortal. Wkly Rep. 2019, 68, 157-164. [CrossRef]

38. King, B.A.; Gammon, D.G.; Marynak, K.L.; Rogers, T. Electronic Cigarette Sales in the United States, 2013-2017. JAMA. 2018, 320, 1379-1380. [CrossRef]

39. Vallone, D.M.; Cuccia, A.F.; Briggs, J.; Xiao, H.; Schillo, B.A.; Hair, E.C. Electronic cigarette and juul use among adolescents and young adults. JAMA Pediatr. 2020, 174, 277-286. [CrossRef] [PubMed] 
40. Protano, C.; Andreoli, R.; Mutti, A.; Manigrasso, M.; Avino, P.; Vitali, M. Reference intervals for urinary cotinine levels and the influence of sampling time and other predictors on its excretion among Italian schoolchildren. Int. J. Environ. Res. Public Health. 2018, 15, 817. [CrossRef] [PubMed]

41. Protano, C.; Andreoli, R.; Manini, P.; Guidotti, M.; Vitali, M. A tobacco-related carcinogen: Assessing the impact of smoking behaviours of cohabitants on benzene exposure in children. Tob Control 2012, 21, 325-329. [CrossRef] [PubMed]

42. Torres, S.; Merino, C.; Paton, B.; Correig, X.; Ramírez, N. Biomarkers of exposure to secondhand and thirdhand tobacco smoke: Recent advances and future perspectives. Int. J. Environ. Res. Public Health 2018, 15, 2693. [CrossRef]

43. Manigrasso, M.; Protano, C.; Vitali, M.; Avino, P. Nanoparticle behaviour in an urban street canyon at different heights and implications on indoor respiratory doses. Atmosphere 2019, 10, 772. [CrossRef]

44. Bo, M.; Salizzoni, P.; Clerico, M.; Buccolieri, R. Assessment of indoor-outdoor particulate matter air pollution: A review. Atmosphere 2017, 8, 136. [CrossRef]

(C) 2020 by the authors. Licensee MDPI, Basel, Switzerland. This article is an open access article distributed under the terms and conditions of the Creative Commons Attribution (CC BY) license (http://creativecommons.org/licenses/by/4.0/). 